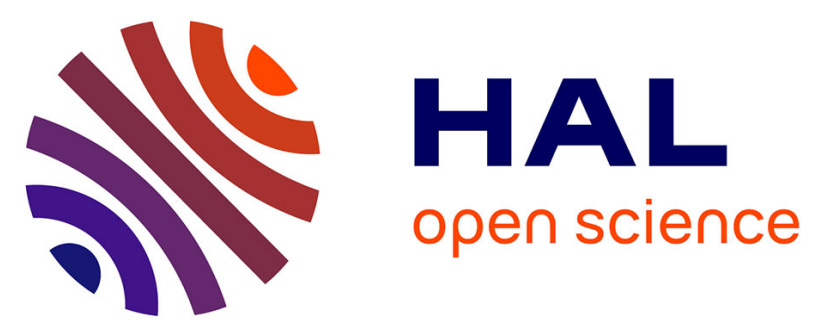

\title{
In vitro probiotic properties of selected lactobacilli and multi-strain consortium on immune function, gut barrier strengthening and gut hormone secretion
}

Yanath Belguesmia, Jeanne Alard, Rezak Mendil, Rozenn Ravallec, Corinne Grangette, Djamel Drider, Benoit Cudennec

\section{To cite this version:}

Yanath Belguesmia, Jeanne Alard, Rezak Mendil, Rozenn Ravallec, Corinne Grangette, et al.. In vitro probiotic properties of selected lactobacilli and multi-strain consortium on immune function, gut barrier strengthening and gut hormone secretion. Journal of Functional Foods, 2019, 57, pp.382-391. 10.1016/j.jff.2019.04.028 . hal-02617752

\section{HAL Id: hal-02617752 \\ https://hal.inrae.fr/hal-02617752}

Submitted on 22 Oct 2021

HAL is a multi-disciplinary open access archive for the deposit and dissemination of scientific research documents, whether they are published or not. The documents may come from teaching and research institutions in France or abroad, or from public or private research centers.
L'archive ouverte pluridisciplinaire HAL, est destinée au dépôt et à la diffusion de documents scientifiques de niveau recherche, publiés ou non, émanant des établissements d'enseignement et de recherche français ou étrangers, des laboratoires publics ou privés.

\section{()ㅜ(1)}

Distributed under a Creative Commons Attribution - NonCommerciall 4.0 International 
$1 \quad$ In vitro probiotic properties of selected lactobacilli and multi-

2 strain consortium on immune function, gut barrier strengthening

\section{and gut hormone secretion}

4

barrier
${ }^{1}$ EA 7394, ICV-Institut Charles Viollette, UniversitéLille, INRA, ISA, UniversitéArtois, Université Littoral Côte d'Opale, F-59000 Lille, France

${ }^{2}$ Univ. Lille, CNRS, Inserm, CHU Lille, Institut Pasteur de Lille, U1019 - UMR 8204 CIIL- Centre d'Infection et d'Immunité de Lille, F-59000 Lille, France'

${ }^{\#}$ These authors contributed equally to this work

*Corresponding author.

Email: benoit.cudennec@univ-lille.fr 


\begin{abstract}
Lactobacillus reuteri ICVB395, L. gasseri ICVB392 and L. gasseri ICVB396 strains, isolated from vaginal microbiota, were investigated for their probiotic traits. L. reuteri ICVB395 strain and the 3RG consortium, associating these three Lactobacillus strains, showed the best antiinflammatory profile on peripheral blood mononuclear cell (PBMC) while L. gasseri ICVB392 was the most potent together with the 3RG consortium to strengthen a Caco-2derived epithelial barrier. The three studied strains induced various secretion levels of glucagon-like peptide 1 (GLP-1) and cholecystokinin (CCK) by STC-1 enteroendocrine cells, whereas the $3 R G$ consortium was globally less performing. Specific antagonists of protein $G$ receptors, CaSR (Calcium-Sensing Receptor) and GPRC6A (G protein-coupled receptor family C group 6 member A), and inhibitor of the peptide transporter Pept-1 provoked differential modulation of the GLP-1 and CCK secretion by STC-1 cells, indicating that different mechanisms are involved in the capacity of lactobacilli and the $3 \mathrm{RG}$ to modulate gut hormones secretion.
\end{abstract}




\section{Introduction}

The gastro-intestinal tract houses billions of microorganisms, namely the gut microbiota, dominated by bacteria, and characterized by their extreme diversity and their key role in the gut homeostasis (Arulampalam, Greicius, \& Pettersson, 2006; Sanders, 2016; Stubbendieck, Vargas-Bautista, \& Straight, 2016). Nowadays this rich and opulent gut microbiota is generally considered as a full microbial "endocrine organ" (Clarke et al., 2014; Jayasinghe, Chiavaroli, Holland, Cutfield, \& O’Sullivan, 2016). Amongst multitude roles of this microbiota we can quote the protection of the host against the invasion of unwanted microorganisms, the contribution to the proper functioning of the immune system, its influence on glucose and lipid homeostasis, and its role on the degradation of insoluble dietary fibres in short chain fatty acids known to exhibit a beneficial impact on the antiinflammatory and metabolic responses (Delzenne \& Cani, 2011; Drissi, Raoult, \& Merhej, 2017; Sánchez et al., 2017). Nonetheless the gut microbiota has also a function of "dialogue" with the digestive tract, interacting with the intestinal cells (Cani \& Knauf, 2016). The diversity of the gut microbiota can be overthrown by drastic changes related to clinical practice and external pressure, notably the mode of delivery and new-borns feeding, medical treatments such as antibiotic, nutrition and health care behaviours and environmental exposure. This can disrupt temporarily the balance of this complex ecosystem leading to digestive discomfort, and the development of chronic diseases (Beaugerie \& Petit, 2004; Quigley, 2013). These perturbations are associated with a dramatic increase in incidence of immune-mediated diseases including allergic and inflammatory bowel diseases but also metabolic diseases including obesity and diabetes and most likely neurodegenerative and psychiatric diseases (Cani \& Knauf, 2016; Doré, Multon, Béhier, \& participants of Giens XXXII, Round Table No. 2, 2017; Fernandez, Lasa, \& Man, 2014). Therefore, the development of approaches targeting the key features of this altered host-microbes 
interactions are highly relevant. Probiotics precisely aimed at preserving and/or restoring the balance of this delicate ecosystem and therefore respond to the precise definition emitted in 2002 by the Food and Agriculture Organisation (FAO) and World Health Organization (WHO), establishing that probiotics are "live microorganisms which, when ingested in adequate amounts, exert positive effects on health, beyond traditional nutritional effects" (FAO/WHO, 2002). Probiotic bacteria, mainly belonging to the Lactobacillus or Bifidobacterium genera, are natural inhabitants of the gastrointestinal (GI) tract (Vaughan \& Mollet, 1999). Probiotics have to survive to the passage through the stomach and the upper part of the small intestine before reaching their site of action to provide their benefits (Fooks \& Gibson, 2002). To overcome this challenge, the selection of potential probiotics bacteria mainly focus on their ability to survive to the harsh conditions of the GI tract (Morelli, 2000). Probiotics could be provided as a unique individual strain or as combination of multiple strains. Multi-strain cocktails could present many advantages providing more benefits compared to those of microorganisms taken alone (Timmerman, Koning, Mulder, Rombouts, \& Beynen, 2004). Indeed, combining multiple strains belonging to different species able to colonize different parts of the digestive tract could be more effective to restore gut homeostasis and to express their positive effects, as these strains can work simultaneously on the different potential causes of the observed disorders (Collado, Meriluoto, \& Salminen, 2007; Timmerman et al., 2004). Use of consortium strains could be justified by the individual specific response of the host, as natural probiotic predominant species can vary from one individual to another. Each strain also helps to generate specific enzyme activities and can stimulate the immune system by different pathways (Sánchez et al., 2017). Bacteria belonging to the two main families of known probiotics are found in various locations in the intestine. Lactobacilli are natural residents of the small intestine while the bifidobacteria are dominant in the colon, their natural habitat (Collado et al., 2007; Gionchetti, Lammers, Rizzello, \& 
Campieri, 2005; Perdigon, Galdeano, Valdez, \& Medici, 2003; Timmerman et al., 2004). Most lactobacilli and bifidobacteria species are considered as GRAS “Generally Recognized As Safe" (Hugas \& Monfort, 1997). The benefits of these bacteria are well known for decades and many traditional and commercial probiotic preparations contain them (Di Cerbo, Palmieri, Aponte, Morales-Medina, \& Iannitti, 2015; Drissi et al., 2017). Probiotic strains express their benefits by strengthening of the intestinal barrier, regulating sugar and lipid metabolism, reducing inflammation or preventing pathogens invasion (Botta, Langerholc, Cencič, \& Cocolin, 2014; Di Cerbo et al., 2015; Park, Oh, \& Cha, 2014; Takemura, Okubo, \& Sonoyama, 2010). Moreover probiotics, especially lactobacilli, synthesize a wide variety of proteases, implied in the food maturation process such as in fermented cheeses (Liu, Bayjanov, Renckens, Nauta, \& Siezen, 2010). Amongst which, serine proteases are produced by many lactobacilli species, notably by L. gasseri, L. plantarum and some L. acidophilus strains (Law \& Haandrikman, 1997; Margono, Sumaryono, Malik, \& Sadikin, 2014). Moreover they produce, lactic acid promoting the balance of intestinal $\mathrm{pH}$, and sometimes antimicrobial substances that inhibit the growth of pathogens (Drissi et al., 2017).

Furthermore, recent works established that probiotic lactobacilli are able to interact with intestinal cells and induce modulation of gut hormones; as glucagon-like peptide-1 (GLP-1); cholecystokinin (CCK) and PYY peptide (Panwar et al., 2016; Yadav, Lee, Lloyd, Walter, \& Rane, 2013). These hormones, because of their influence in food intake regulation and glucose homeostasis, represent promising lever to manage and reduce chronic metabolic diseases like obesity and associated type 2-diabetes (Caron, Domenger, Dhulster, Ravallec, \& Cudennec, 2017).

During a previous work, some Lactobacillus strains, isolated form the vaginal microbiota, exhibited many traits of probiotics microorganisms, including good survivability in the harsh conditions of the GI tract and adhesion to epithelial cells without toxicity (Belguesmia et al., 
117 2016). During these researches some strains, including L. gasseri ICVB392, L. reuteri

118 ICVB395 and L. gasseri ICVB396, initially designated CMUL34, CMUL67 and CMUL80

119 respectively, and renamed after re-identification by $16 \mathrm{~S}$ rDNA sequencing, appeared good

120 potential probiotics and were able, in vitro, to modulate gut hormone expression and secretion

121 in murine enteroendocrine STC-1 cells.

122 The aim of this study is to investigate further probiotic traits of these strains, alone and

123 associated in a consortium. We first evaluated their immunomodulation abilities and their

124 capacity to strengthen the intestinal barrier. Using the enteroendocrine STC-1 cell line, we

125 also studied deeper the impact of the consortium on the secretion of gut hormones, and we

126 unravelled how the bacteria interacted with the cells. Finally, we studied their capacity to

127 limit lipid accumulation in adipocytes.

\section{Material and methods}

\subsection{Bacterial strains}

132 The three Lactobacillus strains used in this research work were previously isolated from

133 Lebanese vaginal microbiota (Al Kassaa, Hamze, Hober, Chihib, \& Drider, 2014), and

134 recently selected for their probiotic traits (Belguesmia et al., 2016). Previously named

135 CMUL34, CMUL67 and CMUL80, they were re-identified by 16S rDNA sequencing and

136 registered in the Institut Charles Viollette Laboratory Collection, under L. gasseri ICVB392,

137 L. reuteri ICVB395 and L. gasseri ICVB396 strains respectively. The strains were also

138 associated in equal amount within the multi-strain cocktail designated during this study as

$1393 \mathrm{RG}$ consortium. Before each experiment, the strains were grown for $18-24 \mathrm{~h}$ at $37^{\circ} \mathrm{C}$ in de

140 Man-Rogosa-Sharpe (MRS) medium (De Man, Rogosa, \& Sharpe, 1960). Two additional

141 strains were used as control strains for immune cells stimulation: Bifidobacterium longum IPL 
142 A7.5 was grown at $37^{\circ} \mathrm{C}$ in anaerobic condition (GENbag anaer, Biomérieux, France) in MRS

143 (Difco, Detroit, USA) supplemented with 0.1\% (w/v) L-cysteine hydrochloride (Sigma) and

144 Lactococcus lactis MG1363 was cultured at $30^{\circ} \mathrm{C}$, in M17 Broth supplemented with $0.5 \%$

145 glucose (Difco, Detroit, USA). For in vitro studies (stimulation of PBMCs, Caco-2 epithelial

146 barrier and adipocytes), bacteria were grown overnight, washed twice in sterile phosphate

147 buffered saline (PBS) buffer $\mathrm{pH} 7.2$ and resuspended at a final concentration of $2 \times 10^{9}$

148 cfu.mL $L^{-1}$ in PBS.

\subsection{In vitro immunomodulation assays}

151 Blood samples from five different healthy adult donors were obtained at the Etablissement

152 Français du Sang (French National Blood Service), in accordance with our institution

153 committees (INSERM, CNRS and Institut Pasteur de Lille, agreement $N^{\circ}$ DC 2013-2022).

154 Peripheral Blood Mononuclear Cells (PBMCs) were isolated from the blood as already

155 described (Foligne et al., 2007). Briefly, after Ficoll gradient centrifugation (GE Healthcare

156 Bio-Sciences, Uppsala, Sweden), mononuclear cells were collected, washed in RPMI-1640

157 medium (Gibco, Life Technologies, Ghent, Belgium), and adjusted to $2 \times 10^{6}$ cells per $\mathrm{mL}$ in

158 RPMI supplemented with gentamicin $\left(150 \mu \mathrm{g} \cdot \mathrm{mL}^{-1}\right)$, L-glutamine $(2 \mathrm{mM})$, and $10 \%$ heat-

159 inactivated FCS (Gibco, Life Technologies, Ghent, Belgium). PBMCs were stimulated with

160 phosphate-buffered saline (PBS, Gibco, Life Technologies, Ghent, Belgium) or bacteria at a

161 bacteria-to-cell ratio of $10: 1$ for $24 \mathrm{~h}$ at $37{ }^{\circ} \mathrm{C}$ with $5 \% \mathrm{CO}_{2}$. The supernatants were collected

162 and stored at $-20^{\circ} \mathrm{C}$ until cytokines (IL-10 IL-12 and IFN- $\gamma$ ) measurements performed using

163 R\&D Duoset ELISA kits (R\&D, Minneapolis, MN, USA). B. longum and Lactococcus lactis

164 were used as positive control for the induction of anti-inflammatory (IL-10) and Th-1/pro-

165 inflammatory (IL-12 and IFN- $\gamma$ ) cytokine secretion by PBMCs, respectively. 
168 The human colon epithelial cell line Caco-2 clone TC7 (Chantret et al., 1994) was used to study the impact of the lactobacilli on trans-epithelial electric resistance (TEER). The Caco-2 cells were grown at $37^{\circ} \mathrm{C}$ with $10 \% \mathrm{CO}_{2}$ in DMEM supplemented with $5 \%$ heat-inactivated

171 foetal calf serum (FCS, Gibco, Life technologies, Ghent, Belgium), 1\% Non-Essential Amino

172 Acids (Gibco, Life Technologies, Ghent, Belgium), $100 \mathrm{U}_{\mathrm{mL}}^{-1}$ penicillin and $100 \mu \mathrm{g} \cdot \mathrm{mL}^{-1}$

173 streptomycin (Gibco, Life Technologies, Ghent, Belgium) and 2mM L-glutamine (Gibco, Life 174 Technologies, Ghent, Belgium).

175 For the permeability test, polarized Caco-2 monolayers were prepared by growing the 176 epithelial cells on 12-wells Transwell® insert filters (polycarbonate membrane with $3 \mu \mathrm{m}$ 177 pore size, $12 \mathrm{~mm}$ diameters, Costar, Corning Life Science, Kennebunk, ME, USA) at a 178 density of $10^{5}$ cells per $\mathrm{cm}^{2}$. The medium was changed every two days until 14 days when 179 optimal trans-epithelial resistance (TEER $\geq 1800 \Omega / \mathrm{cm}^{2}$ ) was reached (which was measured 180 every 2 days $1 \mathrm{~h}$ after changing medium using a millicell-ERS (Electrical Resistance System; 181 Millipore, Billerica, MA, USA). At day 14, fresh medium without FCS was added and cells 182 were treated, in the apical compartment with bacteria (or not) at a bacteria-to-cell ratio of 10:1, 18330 min before the addition of hydrogen peroxide $\left(\mathrm{H}_{2} \mathrm{O}_{2}\right)$ in both basal and apical compartment 184 (at $100 \mu \mathrm{M}$ final concentration). TEER was measured before $\mathrm{H}_{2} \mathrm{O}_{2}$ addition (T0) and every 30 185 min until $120 \mathrm{~min}$. The results were compared to non-treated cells. Three different 186 experiments were performed including duplicates of each condition and results were 187 expressed in \% TEER compared to T0 \pm SEM.

\subsection{Lipid accumulation in adipocytes}

190 The effect of lactobacilli on lipid accumulation in adipocytes was studied using the pre191 adipocyte $3 \mathrm{~T} 3-\mathrm{L} 1$ murine cell line. The $3 \mathrm{~T} 3-\mathrm{L} 1$ cells were grown at $37^{\circ} \mathrm{C}$ with $5 \% \mathrm{CO}_{2}$ in 
192 DMEM supplemented with $10 \%$ heat-inactivated FCS, $100 \mathrm{U}^{\mathrm{mL}} \mathrm{m}^{-1}$ penicillin and $100 \mu \mathrm{g} \cdot \mathrm{mL}^{-}$

$193{ }^{1}$ streptomycin and $2 \mathrm{mM}$ L-glutamine. Cells were used between the $10^{\text {th }}$ and the $16^{\text {th }}$ passage.

194 The 3T3-L1 cells were distributed in 12-wells plates at a concentration of 3500 cells per wells

195 and were differentiated in adipocytes according to the protocol described by (Zebisch, Voigt,

196 Wabitsch, \& Brandsch, 2012). Briefly, cells were grown in medium supplemented with 0,5

$197 \mathrm{mM}$ 3-isobutyl-1methylxanthine, $1 \mu \mathrm{g} \cdot \mathrm{mL}^{-1}$ insulin and $0.25 \mu \mathrm{M}$ dexamethasone. After 48h,

198 fresh medium supplemented with only insulin $\left(1 \mu \mathrm{g} \cdot \mathrm{mL}^{-1}\right)$ was replaced. Basal medium was

199 changed every two days for 10 days, until cells were differentiated in mature adipocytes. Cells

200 were then stimulated for $24 \mathrm{~h}$ with bacteria (or not) at a bacteria-to-cell ratio of 10:1, in fresh

201 medium in the presence of $150 \mu \mathrm{g} \cdot \mathrm{mL}^{-1}$ gentamicin. Lipid accumulation was quantified by

202 Oil- Red-O staining. Briefly, cells were stained using $1 \mathrm{ml}$ ready-to-use Oil-red O solution

203 (DiaPath, Martinengo, Italy) for 15 min., washed 3 times with PBS (Gibco, Life Technologies,

204 Ghent, Belgium). Oil-Red-O was eluting with isopropanol for 30 min incubation. Optic

205 density was measured at $490 \mathrm{~nm}$ by a spectrophotometer ( $E L_{x} 808$, Biotech instruments). The 206 percentage of Oil-red-O stained cells relative to control cells without bacteria was calculated 207 as (A490nm [probiotic sample]/A490nm[control])*100.

\subsection{Gut hormones secretion study}

The STC-1 murine cell line, derived from the intestinal tumour of double transgenic mice,

211 gratefully received from Dr. C. Roche (INSERM U865, Lyon, France), was used for gut

212 hormones study. The cells were grown in Dulbecco's Modified Eagle's Medium (DMEM,

213 Invitrogen, France), supplemented with $10 \%$ foetal bovine serum, $5 \mathrm{mM}$ of L-glutamine and $214100 \mathrm{U} \cdot \mathrm{mL}^{-1}$ of penicillin and streptomycin, at $37^{\circ} \mathrm{C}$ in $5 \% \mathrm{CO}_{2}-95 \%$ air atmosphere. The 215 STC-1 cells were passed twice a week, and were used between the $60^{\text {th }}$ and the $65^{\text {th }}$ passage 216 for the different assays. STC-1 cells were seeded in 24 wells plate at 40,000 cells/well and 
were grown in DMEM culture medium for 48-72h. Cells were washed twice with Hepes 218 buffer without glucose $\left(\mathrm{NaCl} 140 \mathrm{mM}\right.$, Hepes $20 \mathrm{mM}, \mathrm{KCl} 4.5 \mathrm{mM}, \mathrm{CaCl}_{2} 1.2 \mathrm{mM}, \mathrm{MgCl}_{2}$ $2191.2 \mathrm{mM}$, adjusted to $\mathrm{pH} 7.4$ with $\mathrm{NaOH} 3 \mathrm{M}$ ) and then co-incubated with $10^{8} \mathrm{CFU} . \mathrm{mL}^{-1}$ of the 220 selected Lactobacillus strains, alone or in combination, for 8 hours at $37^{\circ} \mathrm{C}$ in $5 \% \mathrm{CO}_{2}-95 \%$ 221 air atmosphere. Purified peptidoglycan from L. acidophilus (Macho-Fernandez et al., 2011), 222 and purified flagellin from Salmonella enterica serovar Typhimurium (gratefully supplied by 223 Dr Jean Claude Sirard from Institut Pasteur de Lille) were tested at 50 and $10 \mu \mathrm{g} \cdot \mathrm{mL}^{-1}$ 224 respectively, to evaluate their impact on gut hormones secretion. The resulting supernatants 225 were centrifuged (8000 g for $10 \mathrm{~min}$ ) and were kept at $-20^{\circ} \mathrm{C}$. GLP-1 and CCK quantifications 226 were realized by Radio-Immuno Assay (RIA) using EMD Milipore (USA) and Cisbio 227 International (France) kits for each hormone, respectively.

228 To examine the capacity of bacteria to degrade the gut hormones, pure active GLP-1 1-26 229 (EMD Milipore, USA) and CCK8S (Sigma Aldrich Merk, Germany) peptide hormones were 230 used at initial concentration of $800 \mathrm{pM}$ and $600 \mathrm{pM}$, respectively. Lactobacilli (at $10^{7}$ 231 CFU.mL ${ }^{-1}$ ) were incubated in Hepes buffer solution containing active GLP-1 or CCK8S, in 232 presence or absence of DPP-IV enzyme inhibitor (Ile-Pro-Ile, Sigma-Aldrich Germany) at 1 $233 \mathrm{mg} \cdot \mathrm{mL}^{-1}$, during $8 \mathrm{~h}$ at $37^{\circ} \mathrm{C}$. The supernatants were recovered by centrifugation at $8000 \mathrm{~g}$, $2344^{\circ} \mathrm{C}$ for $10 \mathrm{~min}$, and quantification of remaining active GLP- 1 or CCK8S in the supernatants 235 was performed by RIA as previously described. Negative control without bacteria was 236 incubated in the same conditions for both hormones. The results were expressed in percentage 237 of initial concentration of active GLP-1 or CCK8S.

238 The effects of CaSR and GPRC6A antagonists and Pept-1 inhibitor on the secretion of GLP-1 239 and CCK hormones by STC-1 after contact with selected Lactobacillus strains were studied. 240 The two antagonists and the inhibitor were prepared according to the suppliers 241 recommendations. NPS 2143 (Sigma Aldrich, Merck Germany), CpD (Enamine, Ukraine), 
and 4-aminomethylbenzoic acid (AMBA-4, Sigma Aldrich, Merck Germany) were used at a

243 final concentration of $25 \mu \mathrm{M}, 50 \mu \mathrm{M}$ and $10 \mathrm{mM}$ in Hepes Buffer, respectively. The STC-1

244 cells were washed after reaching $80 \%$ confluence culture and were incubated for 15 minutes 245 at $37^{\circ} \mathrm{C}$ in $5 \% \mathrm{CO}_{2}-95 \%$ air atmosphere with $100 \mu \mathrm{L}$ of described above solutions. Then the 246 treated STC-1 cells were incubated with lactobacilli in the same conditions as described above.

\subsection{RT-PCR analysis}

249 The relative transcript levels of PepT1 (Peptide transporter) and $\beta$-actin were analysed by 250 quantitative real-time PCR. Briefly, total RNA was extracted from cultured cells using the 251 NucleoSpin ${ }^{\circledR}$ RNA XS (Macherey-Nagel, Germany) according to the manufacturer's 252 instructions. Concentration and purity of each sample were evaluated on a NanoDrop Lite 253 (Thermo Scientific, USA). cDNA was obtained by reverse transcription on a Mastercycler 254 gradient (Eppendorf, Germany) using the RevertAid H Minus First Strand cDNA Synthesis 255 Kit (Thermo Scientific, USA). Finally, reverse transcribed cDNAs were quantified by 256 comparative $\mathrm{Ct}$ experiment on a StepOne ${ }^{\mathrm{TM}}$ Plus system (Applied BioSystems, Life 257 Technologies, USA) using the Power SYBR Green PCR Master Mix (Applied BioSystems, 258 Life Technologies, USA) and specific oligonucleotides: forward (F) 5'259 ACACCCTTAACGAGATGGTCAC-3' and reverse (R) 5'-CCGCCGTGGTGTTTATTGTG260 3' for PepT1 and (F) 5'-TGCCCTGAGGCTCTTTTCCA-3' and (R) 5'261 GGCATAGAGGTCTTTACGGATGTC-3' for $\beta$-actin, all purchased from Eurogentec 262 (France). The cycling conditions were $10 \mathrm{~min}$ at $95{ }^{\circ} \mathrm{C}, 40$ cycles of $15 \mathrm{sec}$ at $95{ }^{\circ} \mathrm{C}, 30 \mathrm{sec}$ at 26360 or $61{ }^{\circ} \mathrm{C}$ and $30 \mathrm{sec}$ at $72{ }^{\circ} \mathrm{C}$, followed by a melting curve step.

\subsection{Statistical analysis}


Data were expressed as mean \pm standard deviation $(\mathrm{SD})$ calculated over three independent experiments performed in triplicate. SigmaPlot 11.0 software (Germany) was used to carry out statistical analysis. One-Way ANOVA followed by a pairwise comparison with Tukey's test was used for comparison of data with normal distribution. p values $<0.05$ were regarded as significant.

\section{Results}

\subsection{Immunomodulatory capacities of the lactobacilli}

The three Lactobacillus strains, incubated alone and in 3RG multi-strain consortium with the peripheral blood mononuclear cells induced different cytokine secretion profiles. The two conversely to L. reuteri ICVB395 strain which induced significant levels in comparison to 278 untreated cells, reaching similar level $\left(900\right.$ pg.mL $\left.\mathrm{m}^{-1}\right)$ observed with the control anti279 inflammatory strain B. longum. The consortium 3RG was also able to induce IL-10 secretion 280 after PBMC stimulation, but at a lower level, reaching approximately $400 \mathrm{pg} \cdot \mathrm{mL}^{-1}$ despite no significant difference when compared to the control (Figure 1A). The three individual Lactobacillus strains and the 3RG consortium were not able to induce detectable IL-12 and 283 IFN $\gamma$ secretion by PBMC (Figure 1B, 1C), while the control L. lactis strain induced significant amount of these two Th1/pro-inflammatory cytokines.

\subsection{Capacity of the strains to strengthen the epithelial barrier}

287 We evaluated the capacity of the strains to restore the gut barrier function using an in vitro 288 model of $\mathrm{H}_{2} \mathrm{O}_{2}$-sensitized Caco-2 cells monolayers, as previously reported (J. Alard et al., 2018). As expected, $\mathrm{H}_{2} \mathrm{O}_{2}$ sensitization induced permeability as shown by a significant and 
able to restore the epithelial barrier, as shown by an increase in the TEER as compared to

$292 \mathrm{H}_{2} \mathrm{O}_{2}$-sensitized control cells (Figure 2), which was however not significant for L. gasseri 293 ICVB396 and L. reuteri ICVB395 which was able to maintain the TEER at the level of 294 untreated control only until $60 \mathrm{~min}$. Interestingly, the 3RG consortium and the L. gasseri 295 ICVB392 strain not only restored but even reinforced the epithelial barrier, the TEER being 296 higher than the $\mathrm{H}_{2} \mathrm{O}_{2}$ non-sensitized control monolayer.

\subsection{Impact on lipid accumulation in adipocytes}

299

Lipid accumulation observed in 3T3-L1 derived mature adipocytes treated with the 300 lactobacilli were generally lower than the level found in non-treated adipocytes. The most 301 important reduction was observed with the L. reuteri ICVB395 and L. gasseri ICVB396 302 strains, which induced significant drop of lipid level comparatively to the control, reaching 303 respectively $30 \%$ and $20 \%$ decrease in comparison to the control level (Figure 3). The third strain, L. gasseri ICVB392, as well as the 3RG consortium showed also a similar tendency which was however not significant (Figure 3).

\subsection{Capacity of the lactobacilli strains to modulate gut hormones secretion}

\subsubsection{Effects on active-GLP-1 secretion}

309 We evaluated the capacity of the strains to induce the release of GLP-1 using the STC-1 310 enteroendocrine cell line. After 8 hours bacterial stimulation of STC-1 cells, the highest GLP3111 secretion was obtained with $L$. gasseri ICVB392 and L. reuteri ICVB395, which induced 312 hormone secretion estimated to 6 fold higher than the control level. L. gasseri ICVB396 and 313 the 3RG consortium induced also significant GLP-1 release, which was, however lower, 314 reaching 4 fold and 3 fold of the control GLP-1 secretion level, respectively (Figure 4A). 


\subsubsection{Effects on CCK secretion}

317 The Lactobacillus strains tested in this study exhibited moderate impact on the CCK secretion 318 by stimulated STC-1 cells (Figure 4B). L. reuteri ICVB395 and L. gasseri ICVB396 showed 319 the most important effect inducing significant CCK secretion, reaching level more than one 320 fold and half of the control level. The association of these strain with L. gasseri ICVB392, in 321 the 3RG consortium leaded to a decrease of the quantified CCK level compared to those 322 obtained with ICVB395 and ICVB396 tested alone (Figure 4B). Purified peptidoglycan from L. acidophilus and flagellin from S. enteritidis serovar Thyphimirium didn't stimulate the secretion of both CCK and GLP-1 by STC-1 cells (data not shown).

\subsubsection{Investigation of the different pathways involved on gut hormone secretion modulation}

Since GLP-1 and CCK secretion are under the influence of three major signalling pathways implying protein $\mathrm{G}$ receptors, notably the calcium-sensing receptor (CaSR) and the GPR family C group 6 member A (GPRC6A), and the di/tripeptide transporter 1 (Pept1), we evaluated their respective role using CaSR and GPRC6A antagonists and Pept-1 inhibitor.

We first studied Pept-1 gene expression in the enteroendocrine STC-1 cells. RT-PCR analysis unveiled a significant gene expression of Pept-1with CT value obtained of $26.47 \pm 0.44$ while reference $\beta$-actin gene expression showed CT of $14.02 \pm 0.22$ (data not shown)

334 The addition of CaSR and GPRC6A antagonists induced a significant decrease of GLP-1 secretion induced by the stimulation of the STC-1 cells with the lactobacilli alone or with the 3RG consortium, except for GPRC6A inhibitor with ICVB396 strain (Figure 4A). Analysis of 337 effect of CaSR antagonist indicated that the most important decrease is observed for the ICVB392 and ICVB395 strains for which the GLP-1 level decreased from 6 to around 4 fold

339 the control level. The GLP-1 secretion level reduction observed for the ICVB396 strain and 340 the $3 R G$ consortium was moderate decreasing from 4 to 2.5 fold and from 3 to less than 2 fold 
341 of the control level, respectively. Regarding the effect of the GPRC6A antagonist, we 342 observed more or less the same effect with major decrease for the ICVB392 and ICV395 343 strains, and moderate for the 3RG consortium. However the decrease of GLP-1 level 344 measured for the ICV396 pre-treated STC-1 was not significant (Figure 4A). Interestingly 345 Pept-1 inhibitor induced a reduction of GLP-1 secretion for all strains and the 3RG 346 consortium, nearly to the same levels obtained with GPRC6A inhibitor, except for the strain 347 ICVB395 for which GLP-1 secretion was not impacted by AMBA-4 Pept-1 inhibitor.

348 The results obtained for CCK were slightly different, as we observed a statistically significant 349 effect just for the ICVB396 strains and 3RG consortium after pre-treatment with CaSR 350 antagonist. GPRC6A and Pept-1 antagonist and inhibitor didn't appear to affect the CCK 351 secretion level in a significant manner in all cases studied in this work, excepted for a slight 352 effect which was observed with Pept-1 inhibitor and GPRC6A antagonists on the effect of 353 ICVB392 strain and the 3RG consortium respectively (Figure 4B).

\subsubsection{Capacity of selected lactobacilli strains to degrade GLP-1 1-26 and CCK8S}

356 When the GLP-1 1-26 (800 pM) and CCK8S (600 pM) peptide solutions (Figure 5, black 357 bars) were incubated with the selected strains and the consortium for $8 \mathrm{~h}$, significant decreases 358 of peptides were observed in the presence of $L$. gasseri ICVB396 and the 3RG multi-strains 359 cocktail. Resulting concentrations of around 550 pM of active GLP-1 1-26, and of around 180 360 and 340 pM of CCK8S, were measured after incubation with L. gasseri ICVB396 strain and 361 3RG consortium, respectively. A significant impact was also observed for L. gasseri 362 ICVB392 on the measured amount of CCK with a decrease from 600 to $400 \mathrm{pM}$ after 363 incubation.

364 In the presence of the tripeptide (Ile-Pro-Ile), a DPP-IV inhibitor (grey bars), the consumption 365 of GLP-1 1-26 and CCK8S by L. gasseri ICVB392 and ICVB396 was reduced to nearly the 
control level. However, the DPP-IV inhibitor did not significantly affect the consumption of

367 GLP-1 and CCK by the 3RG consortium (Figure 5 A, B).

\section{Discussion}

370 In the present study, we investigated additional probiotic traits of Lactobacillus strains 371 selected during previous works (Al Kassaa et al., 2014; Belguesmia et al., 2016). We

372 previously established, using Caco-2 cells stimulation, that the three strains, selected in the 373 present study, exhibited promising anti-inflammatory abilities, limiting the level of IL1- $\beta$ 374 induced IL-8 release and inducing the secretion of IL-10 (Belguesmia et al., 2016). It has been 375 pointed out that in vitro immunomodulation assays have to be considered carefully regarding 376 the type and the physiological state of the eukaryotic cell models. Indeed probiotic strains 377 could display different immunomodulatory profiles using epithelial cell model (i.e. HT-29 cell 378 line) and PBMC stimulation used (Kechaou et al., 2013). Taking in account this postulate and 379 in order to consolidate the results obtained on epithelial intestinal cells, we evaluated the 380 immunomodulation capacities of the selected Lactobacillus strains, considered alone or in 381 combination in the 3RG consortium, using in vitro PBMCs stimulation. We notably unravel 382 their ability to induce the secretion of the anti-inflammatory IL-10 versus the Th1/pro383 inflammatory IL-12 and IFN $\gamma$ cytokines, We previously observed that in vitro 384 immunomodulation abilities of lactobacilli are strain-specific and linked to their in vivo 385 protective effects in murine models of colitis (Foligne et al., 2007).

386 We revealed during PBMC study that the $L$. reuteri ICVB395 strain was the most potent 387 strain to induce the secretion of the anti-inflammatory IL-10 cytokine, while the two other $L$. 388 gasseri strains, were not able to induce significant IL-10 response comparatively to the 389 negative control. The $3 \mathrm{RG}$ consortium was able to induce moderate but significant secretion 390 of this interleukin. 
Nonetheless in the present study, none of the strains alone or in the 3RG consortium was able to induce IL-12 or interferon $\gamma($ IFN- $\gamma$ ) which overall remained undetectable (Figure 1C). IL-

39312 cytokine plays an important role in activating the Th1 immune response by promoting the 394 differentiation of naïve T cell to Th1 cells to produce interferon $\gamma$ (IFN- $\gamma$ ) (Meijerink et al., 2012; Watson, Sargianou, \& Panos, 2012). In contrast, IL-10 is known to inhibit natural killer (NK) and Th1 cells, by down-regulating the IL-12 production and facilitating Th2 immune 397 response (Tripp, Wolf, \& Unanue, 1993; Uyemura et al., 1996). The balance between these 398 two interleukins defines the immune response and plays a major role in the anti399 inflammatory/pro-inflammatory state which is dysregulated during colitis, allergy, irritable bowel syndrome and other inflammatory diseases. Indeed, a high IL-10/IL-12 ratio could predict favourable anti-inflammatory abilities of probiotic strains, especially for lactobacilli (Foligne et al., 2007; Meijerink et al., 2012; Watson et al., 2012). Hence the bacterial strains tested showed differential abilities to influence the inflammatory state.

404 Chronic inflammatory diseases are often associated with an increased intestinal permeability known as leaky gut which facilitates the translocation of commensal bacteria, thus contributing to the development of a chronic inflammatory state. We then evaluated the

407 capacity of the strains to strengthen the epithelial barrier using an in vitro model of epithelial 408 barrier. All the strains were able to attenuate the $\mathrm{H}_{2} \mathrm{O}_{2}$-induced permeability. However, the 409 best ability to strengthen the epithelial barrier was observed with L. gasseri ICVB392 and the $4103 \mathrm{RG}$ consortium which were not only able to restore the $\mathrm{H}_{2} \mathrm{O}_{2}$-sensitized monolayer but were 411 also able to reinforce the trans-epithelial resistance. Among studied probiotic properties of 412 microorganisms, TEER assay appeared as a reliable method to anticipate and establish effect 413 of potential probiotics strains on epithelium (J. Alard et al., 2018; Klingberg, Pedersen, 414 Cencic, \& Budde, 2005; Messaoudi et al., 2012). Most studies showed protective effect of 415 probiotic strains, improving permeability of sensitized epithelial monolayer, with some strains 
able also to reinforce the epithelium barrier with increased TEER values over the basal level

417 observed for untreated control epithelium (Anderson et al., 2013; Botta et al., 2014; Ramos,

418 Thorsen, Schwan, \& Jespersen, 2013). Mechanisms implied in this phenomenon are still not

419 completely elucidated and seems to be strain-specific (Anderson et al., 2013; Ramos et al.,

420 2013). Some strains seem to display a negative effect (i.e. L. fermentum RGR1487) whereas

421 other (i.e. L. fermentum RGR1485) have neutral/positive effect on the TEER of Caco-2 cells

422 epithelium (Anderson et al., 2013). Ramos et al. (2013) isolated a number of probiotic

423 lactobacilli, belonging to L. plantarum, L. brevis and L. fermentum species, from different

424 Brazilian food products. Most of these strains showed enhanced TEER, but not at the same

425 level and independently from species consideration. In a previous study, we were also able to

426 select strains (L. acidophilus PI11, L. helveticus PI5 and L. gasseri LA806) able to restore and

427 reinforce the epithelial barrier using the same in vitro model (J. Alard et al., 2018). Recently,

428 Kawano et al., stated that the probiotic L. gasseri SBT2055 (LG2055) exhibits anti-obesity

429 effects by improving the intestinal integrity and thus reducing the entry of inflammatory

430 substances like endotoxin from the gut lumen, which may improve the inflammation state

431 within metabolic organs (Kawano, Miyoshi, Ogawa, Sakai, \& Kadooka, 2016).

432 Another aspect of probiotic property investigated during our study is the ability of the strains

433 to influence the accumulation of lipid in adipocytes. We showed that two of the tested strains

434 (L. reuteri ICV39 and L. gasseri ICV396) induced significant reduction of lipid accumulation

435 in adipocytes. The third strain, L. gasseri ICVB392, doesn't reach such reduction but achieve

436 a lowering tendency. Similar behaviour was also observed for the $3 R G$ consortium containing

437 the three strains with an intermediate effect but a lower efficiency than the L. reuteri

438 ICVB395 and L. gasseri ICVB396 strains considered alone. In previous work, Park et al.,

439 showed that a probiotic strain of L. brevis, designated KLEB, inhibited lipid accumulation in

440 the differentiated 3T3-L1 adipocytes by downregulating the expression of adipogenic 
transcription factors and other specific genes involved in lipid metabolism, leading to the

442 inhibition of adipocyte differentiation, intracellular triglyceride accumulation and a decrease

443 of glycerol-3-phosphate dehydrogenase (GPDH) activity (Park et al., 2014). In an in vivo

444 study using high fat diet-fed C57BL/6 mice, a strain of L. bulgaricus $\mathrm{N}^{\circ} 14$ was clearly able to

445 reduce adipocytes size, the weight of white adipose tissue and the serum leptin and cholesterol

446 levels (Takemura et al., 2010).

447 In a recent review, Drissi et al. analysed the results of experimental and clinical studies which 448 evaluated the impact of lactobacilli on animal and human body weight and reported a strain 449 specific effect. The administration of L. reuteri, L. sakei, L. acidophilus and L. casei was 450 associated with weight gain in human, while the consumption of specific strains of L. gasseri, 451 L. amylovorus, L. plantarum and some L. acidophilus strains was associated with weight loss 452 in obese humans and body fat loss in overweight healthy individuals (Drissi et al., 2017). 453 Stenman et al. also identified promising probiotics for preclinical studies including several 454 Lactobacillus strains, notably L. acidophilus NCFM, L. gasseri 2055, L. reuteri GMNL-263 455 and the multistrain consortium LGG/Bb12 and VSL\#3, which showed proven benefits on 456 insulin insensitivity, fat accumulation and weight loss during in vivo assays in human and 457 animal trials (Stenman, Burcelin, \& Lahtinen, 2016).

458 Gut hormones, notably PYY and GLP-1, released from enteroendocrine cells within the 459 gastrointestinal tract are known to play crucial role not only in the control of satiety and 460 energy balance, but also, notably for GLP-1, numerous effects as incretin hormone on glucose 461 homeostasis (Holst, 2007). GLP-1 was also recently shown to exhibit anti-inflammatory 462 effects and to promote gut barrier integrity (Lebrun et al., 2017). In the present study, using 463 the STC-1 cell line, we confirmed that the selected strains, L. gasseri ICVB392, L. reuteri 464 ICVB395 and L. gasseri ICVB396, were able to modulate the secretion of active GLP-1 and 465 CCK gut hormones. GLP-1 and CCK were demonstrated to be potential targets of probiotic 
preparations to control food intake and regulate the appetite on mouse model (Yadav et al.,

467 2013). Interestingly, the two strains, L. gasseri ICVB392 and L. reuteri ICVB395, induced strong GLP-1 secretion, reaching around 6 fold the control level, while the L. gasseri ICVB396 induced lower amount however reaching 4 fold the basal level. Surprisingly, mixing the 3 strains in the $3 \mathrm{RG}$ consortium seemed to provoke a reduction of the secreted 471 GLP-1, as compared to the levels obtained with individual strains, notably with the two 472 highest ones. Interestingly, we demonstrated that the L. gasseri ICVB396 was able, in contrast 473 to the two other strains, to degrade in vitro the active GLP-1 and this was also observed with 474 the mixture. We can thus hypothesize that the GLP-1 released upon STC-1 stimulation with 475 the L. gasseri strain, or by the $3 R G$ consortium could be under-evaluated following its 476 degradation by proteases. This result was not surprising regarding the diversity of the 477 proteases present in lactobacilli (Law \& Haandrikman, 1997; Liu et al., 2010). Dipeptidyl peptidase IV (DPP-IV) is a prolyl oligopeptidase, member of the serine proteases, able to 479 cleave the incretin hormone GLP-1, playing thus a determinant role on its metabolic and 480 immune functions. Two forms of DPP-IV have been described, a soluble circulating form and 481 a transmembrane serine exopeptidase (Aso et al., 2012). DPP-IV hydrolyses the GLP-1(7-36) 482 amide to generate GLP-1(9-36) amide and the N-terminal histidine-alanine dipeptide 483 (Nadkarni, Chepurny, \& Holz, 2014). We therefore use a competitive inhibitor of the DPP-IV, 484 the Ile-Pro-Ile tripeptide called diprotin A, to ensure that observed consumption, or 485 degradation, of GLP-1 in the STC-1 culture supernatants was not linked to the presence of 486 serine protease DPP-IV-like enzymes produced by the Lactobacillus strains. We showed that 487 the GLP-1 degradation was inhibited by the addition of the competitive inhibitor, while the 488 effect of the 3RG consortium on GLP-1 release seemed to be insensitive to the treatment with 489 the Ile-Pro-Ile tripeptide, maintaining the same decreased level of GLP-1, in the presence or 490 absence of the inhibitor. The peptidic nature of the DPP-IV inhibitor made it susceptible to be 
degraded by enzymes secreted by the other lactobacilli, explaining the absence of inhibitory

492 effects on serine proteases implied in the degradation of GLP-1 1-26 and CCK-8S hormones used in this study. However it is difficult to elucidate the potential effect of enzymes

494 interaction when the three strains consortium partners are mixed in the 3RG multi-strains 495 cocktail. Indeed this interesting observation pointed out the limits of the in vitro models used. 496 However this observation need to be relativized in in vivo conditions, in which GLP-1 is 497 secreted at the basal side of the intestinal epithelium, making the degradation of this hormone 498 by the bacteria not conceivable, since the microorganisms interact with these cells on their 499 apical side (Bohórquez \& Liddle, 2011).

500 Similarly to the results observed on GLP-1, CCK secretion level varied significantly when the 501 three strains were mixed in the 3RG consortium. The three Lactobacillus strains appeared to 502 be able to increase the level of the CCK secreted by the STC-1 cells. Although the CCK level 503 obtained after incubation with the 3RG multi-strains cocktail was lower (by 20\%) than the 504 level obtained with L. reuteri ICVB395 or L. gasseri ICVB396 tested alone. As for GLP-1 505 experiment, we estimate the ability of the selected Lactobacilli strains selected for this study 506 to consume or degrade the CCK8S hormone. We also observed a strong reduction of the 507 CCK8S level when co-incubated with the ICVB392 and ICVB396 strains, or the 3RG 508 consortium. Moreover as for the GLP-1 1-26, the CCK consumption by the two strains was 509 dramatically reduced by the addition of diprotin A. Again, the impact of the 3RG consortium 510 seemed to be insensitive to the addition of the serine protease inhibitor, as the level of the 511 CCK remained the same observed with and without the addition of the diprotin A (Figure 5). 512 This could be explained also in this case by the complex interactions occurring in a multi513 strains mixture between strains and STC-1 cells. Rose et al. established that CCK-8 can be 514 cleaved by serine peptidases, an isoform of tripeptidyl peptidase II notably present in the rat 515 brain, and producing CCK-5 and GWM as major fragments. Interestingly CCK-8 degradation 
was limited by serine-alkylating reagents, permitting recovery of complete initial amount of

517 CCK-8 (C. Rose, Camus, \& Schwartz, 1988; Christiane Rose et al., 1996). Interaction of 518 probiotic preparations with intestinal cells, in the control of gut hormone secretion, is the subject of many researches. Most of them, notably using experimental murine models of 520 obesity, pointed the importance of short chain fatty acids (SCFA), which are bacterial 521 fermentation products of soluble fibers by commensal bacteria, on the food intake and weight 522 regulation (Jeanne Alard et al., 2016; Wang et al., 2015; Yadav et al., 2013). However none of 523 the selected strains used in this study are able to produce the main SCFA involved in energy 524 balance, namely butyrate, propionate or acetate, since no detectable level were measured 525 using gas chromatography analysis in the supernatant of the STC-1 cells culture after $8 \mathrm{~h}$ of 526 incubation with the chosen Lactobacillus strains (data not shown). We then investigated the 527 mechanism involved in the interaction between the lactobacilli strains and the STC-1 cells.

528 Enteroendocrine mammalian cells (EECs) can interact with bacteria, or derived components, 529 through different receptors. The apical portion of enteroendocrine cells, in contact the gut 530 lumen, may sense bacterial inputs through pattern recognition receptors (PRR) such as toll531 like receptors (e.g., TLRs 4, 5, and 9), which are expressed in EECs. Stimulation with 532 bacterial ligands (e.g., LPS or flagellin) following direct contact, have been shown to promote 533 the secretion of gut hormones (Bohórquez \& Liddle, 2011). However many other receptors 534 could be involved in interaction with bacteria, we therefore evaluated other possible pathways 535 which could affect the gut hormones secretion.

536 GLP-1 and CCK secretion are under the influence of three major signalling pathways 537 implying protein $\mathrm{G}$ receptors, notably the calcium-sensing receptor (CaSR) and the GPR 538 family C group 6 member A (GPRC6A), and the di/tripeptide transporter 1 (Pept1), involving 539 ERK 1/2 phosphorylation or proton uptake coupled to peptide transport (Caron et al., 2017). 540 These receptors were demonstrated to be sensitive to the action of peptide fragments and 
amino-acids, and their activation led to the release of GLP-1 and CCK gut hormones in the

542 circulatory system (Caron et al., 2017).

543 Previous research established the expression of the gene encoding Pept-1 in the STC-1 cell

544 line (Liou et al., 2011), while other published work indicated low expression levels

545 (Diakogiannaki et al., 2013). We were able, using quantitative PCR, to highlight pept1 gene

546 expression in the STC-1 cells we used. We therefore evaluate the possible implication of this

547 transporter in the interaction between the Lactobacillus strains and the STC-1 cells, as well as 548 the two GRPs.

549 We demonstrated that the inhibitory action of specific antagonists and inhibitors of those 550 receptors and transporter led to different effects on the impact of the tested strains ICVB392, 551 ICVB395 and ICVB396, and the consortium 3RG. The response to the two strains of $L$. 552 gasseri ICVB392 and the ICVB396 was modified by the antagonists of CaSR and GPRC6A, 553 and the inhibitor of the Pept 1 transporter, leading globally to the decrease GLP-1 secretion in 554 the medium. Although the effect obtained with the L. reuteri ICVB395 strain appeared to be 555 insensitive to the action of the Pept1 inhibitor AMBA-4, interestingly the effects of the 556 inhibitor and antagonists were significant for the $3 R G$ consortium. These observations 557 indicated differential interaction of the Lactobacillus strains with the STC-1 cells involved in 558 GLP-1 secretion. Conversely the effect of Pept1 inhibitors and antagonists of CasR and 559 GPRC6A on CCK secretion were more limited. However the CaSR antagonist and the Pept1 560 inhibitor affected significantly the interaction of STC-1 with L. gasseri ICVB392 and 561 ICVB396, involved in CCK secretion. However the ability of these strains to degrade the 562 GLP-1 and the CCK could minimise the observed induction effects on hormone secretion 563 measured in the supernatant of STC-1 cells culture. The calcium-sensing receptor $(\mathrm{CaSR})$ is a 564 Class C G-protein coupled receptor which senses extracellular levels of calcium ion (Vezzoli, 565 Soldati, \& Gambaro, 2009). Various metabolites could activate CaSR response leading to 
566 GLP-1 and CCK secretion, like $\mathrm{Ca}^{++}$ions and basic L-amino acids like L-phenylalanine

567 (Caron et al., 2017). Previous studies on L. gasseri strains, isolated from vaginal environment, 568 established that those lactic acid bacteria, with good aggregation abilities, possess specific 569 surface protein designated aggregation promoting factor (afp) (Boris, Suarez, \& Barbes, 1997). 570 This protein appeared to contain basic amino acids and phenylalanine residues which can 571 interact with the surface of host cells (Boris et al., 1997; Jankovic et al., 2003).

572 The GPRC6A receptor is a newly deorphanized class C GPCR, for which the first allosteric 573 antagonist, based on the 2-arylindole privileged structure scaffold, was recently reported 574 (Johansson et al., 2015). GPRC6A activation led to initiating signalling cascade, 575 intermediated by Gaq subunit, which induce intracellular $\mathrm{Ca}^{++}$increase and GLP-1 hormone 576 secretion (Caron et al., 2017). Wellendorph et al. established that the GPRC6A was activated 577 by basic $\alpha$-amino acids, L-Argenin, L-Lysine and L-Ornithine being the most active agonists 578 for this receptor. The role of these amino acids in activation of GPRC6A receptor was 579 confirmed by Oya et al. using GLUTag and STC-1 enteroendocrine cell lines. Furthermore 580 GPRC6A receptor antagonists, a phospholipase C inhibitor or an IP3 receptor antagonist, 581 suppress significantly the L-Ornithine-induced intracellular $\mathrm{Ca}^{++}$concentration and GLP-1 582 secretion, identifying the involvement of this pathway in the hormone secretion (Oya et al., 583 2013; Wellendorph et al., 2005).

584 Interestingly, peptides and amino acids are generally sensed by EEC via the proton-coupled 585 peptide-transporter PepT1, this nutrient-sensing being linked to hormone secretion (Zietek \& 586 Rath, 2016). We previously demonstrated that the muropeptide M-tri-Lys, derived from the 587 peptidoglycan of a selected Lactobacillus strain, was able to protect mice from colitis in a 588 NOD2-dependant manner, while the M-tri-Lys-N was not, suggesting that only the M-tri-Lys could be internalized by PepT1 or PepT2 transporters into the cell to interact with the 590 cytosolic receptor NOD2 (Macho-Fernandez et al., 2011). The importance of the main TLR 
adaptator MyD88 was also linked to the increase of GLP-1 and glucose-dependent

592 insulinotropic polypeptide (GIP) secretion when STC-1 cells were co-cultured with

593 Lactobacilli strains (Panwar et al., 2016). Moreover it was established that the modulation of

594 the microbiota/SCFA/bile-acid-signalling, impacted the metabolism and the inflammatory

595 processes via GLP-1 and other markers, representing an interesting target for the treatment of

596 chronic diseases (Zietek \& Rath, 2016).

597 In vitro tests realized during this study showed that the $3 R G$ consortium exhibited different 598 response profiles on GLP-1 and CCK hormone secretion, in comparison to the strains 599 considered alone. However the association of these strains could retain our interest as it could 600 combine the potential of each strain maximizing their combined effect on the metabolism, 601 even if this was not observed in our experimental in vitro conditions. It remains thus 602 important to evaluate such potential in in vivo animal models to definitively establish the 603 beneficial impact of the proposed 3RG consortium.

604 In conclusion our study established that the selected Lactobacillus strains we evaluated in this 605 work, presented interesting probiotic potential regarding in vitro experiment results. Positive 606 impacts on anti-inflammatory cytokine secretion, decrease in lipid accumulation in adipocytes 607 and restoration of the epithelial barrier, were highlighted for ICVB395 strain and in a more 608 limited tendency for 3RG consortium. ICV 392 was the best potent strain to strengthen the 609 epithelial barrier together with the $3 \mathrm{RG}$ consortium. The impact of the lactobacilli on gut 610 hormone GLP-1 and CCK secretion appeared more difficult to analyse due to the limit of the 611 in vitro enteroendocrine STC-1 cell model used. We indeed established that some of the 612 Lactobacillus strains have the ability to degrade the GLP-1 1-26 and CCK-8S, probably, 613 through the action of serine peptidases. To resolve this question a relevant alternative would 614 be to use a polarized EEC in vitro model using insert (transwell) system, in which gut 615 hormones would be secreted at the basolateral compartment while bacteria would be added at 
616 the apical surface. A recent study published by Zhang et al., described such approach using

617 secreting GLP-1 Caco-2 cells grown in vitro on inserts (Zhang, Liu, Chen, \& Luo, 2018).

618 However, since all these in vitro models present certain limits, we plan to unravel the

619 probiotic potential of these strains in appropriate in vivo models to confirm their beneficial

620 capacities in the context of chronic diseases such as IBD and obesity.

\section{Acknowledgments}

623 This work was supported by a grant of the Nord-Pas-de-Calais Region: "2nd appel à projet, 624 Programme projets émergents." It has also been carried out in the framework of Alibiotech 625 project which is financed by the European Union, the French State, and the French Region of 626 Hauts-de-France and was also supported by the Institut Pasteur de Lille and the Centre 627 National de la Recherche Scientifique (CNRS). The experiments were partly performed at 628 IUT A which is gratefully acknowledged.

629

\section{Bibliography}

631 Al Kassaa, I., Hamze, M., Hober, D., Chihib, N.-E., \& Drider, D. (2014). Identification of Vaginal Lactobacilli with Potential Probiotic Properties Isolated from Women in North Lebanon. Microbial Ecology, 67(3), 722-734. https://doi.org/10.1007/s00248014-0384-7

Alard, J., Peucelle, V., Boutillier, D., Breton, J., Kuylle, S., Pot, B., Holowacz, S., Grangette, C. (2018). New probiotic strains for inflammatory bowel disease management identified by combining in vitro and in vivo approaches. Beneficial Microbes, 9(2), 317-331. https://doi.org/10.3920/BM2017.0097 
Beneficial metabolic effects of selected probiotics on diet-induced obesity and insulin resistance in mice are associated with improvement of dysbiotic gut microbiota. Environmental Microbiology. 18(5):1484-97. doi: 10.1111/1462-2920.13181.

644

645

646

647

648

649

650

651

652

653

654

655

656

657

658

659

660

661

662

663

Anderson, R. C., Young, W., Clerens, S., Cookson, A. L., McCann, M. J., Armstrong, K. M., \& Roy, N. C. (2013). Human oral isolate Lactobacillus fermentum AGR1487 reduces intestinal barrier integrity by increasing the turnover of microtubules in Caco- 2 cells. PLoS ONE, 8(11), e78774.

Arulampalam, V., Greicius, G., \& Pettersson, S. (2006). The long and winding road to gut homeostasis. Current opinion in gastroenterology, 22(4), 349-353.

Aso, Y., Ozeki, N., Terasawa, T., Naruse, R., Hara, K., Suetsugu, M., Takebayashi, K., Shibazaki, M., Haruki, K., Morita, K., \& Inukai, T.. (2012). Serum level of soluble CD26/dipeptidyl peptidase-4 (DPP-4) predicts the response to sitagliptin, a DPP-4 inhibitor, in patients with type 2 diabetes controlled inadequately by metformin and/or sulfonylurea. Translational Research, 159(1), 25-31.

Beaugerie, L., \& Petit, J.-C. (2004). Microbial-gut interactions in health and disease. Antibiotic-associated diarrhoea. Best Practice \& Research. Clinical Gastroenterology, 18(2), 337-352. https://doi.org/10.1016/j.bpg.2003.10.002

Belguesmia, Y., Domenger, D., Caron, J., Dhulster, P., Ravallec, R., Drider, D., \& Cudennec, B. (2016). Novel probiotic evidence of Lactobacilli on immunomodulation and regulation of satiety hormones release in intestinal cells. Journal of Functional Foods, $24,276-286$.

Bohórquez, D. V., \& Liddle, R. A. (2011). Axon-like basal processes in enteroendocrine cells: characteristics and potential targets. Clinical and translational science, 4(5), 387-391. 
Boris, S., Suarez, J. E., \& Barbes, C. (1997). Characterization of the aggregation promoting factor from Lactobacillus gasseri, avaginal isolate. Journal of applied microbiology, 83(4), 413-420.

Botta, C., Langerholc, T., Cencič, A., \& Cocolin, L. (2014). In vitro selection and characterization of new probiotic candidates from table olive microbiota. PLoS One, 9(4), e94457.

Cani, P. D., \& Knauf, C. (2016). How gut microbes talk to organs: the role of endocrine and nervous routes. Molecular metabolism, 5(9), 743-752.

Caron, J., Domenger, D., Dhulster, P., Ravallec, R., \& Cudennec, B. (2017). Protein digestion-derived peptides and the peripheral regulation of food intake. Frontiers in endocrinology, 8,85 .

Chantret, I., Rodolosse, A., Barbat, A., Dussaulx, E., Brot-Laroche, E., Zweibaum, A., \& Rousset, M. (1994). Differential expression of sucrase-isomaltase in clones isolated from early and late passages of the cell line Caco-2: evidence for glucose-dependent negative regulation. Journal of Cell Science, 107(1), 213-225.

Clarke, G., Stilling, R. M., Kennedy, P. J., Stanton, C., Cryan, J. F., \& Dinan, T. G. (2014). Minireview: Gut microbiota: the neglected endocrine organ. Molecular Endocrinology (Baltimore, Md.), 28(8), 1221-1238. https://doi.org/10.1210/me.2014-1108

Collado, M. C., Meriluoto, J., \& Salminen, S. (2007). In vitro analysis of probiotic strain combinations to inhibit pathogen adhesion to human intestinal mucus. Food Research International, 40(5), 629-636.

De Man, J. C., Rogosa, deM, \& Sharpe, M. E. (1960). A medium for the cultivation of Lactobacilli. Journal of applied Bacteriology, 23(1), 130-135.

Delzenne, N. M., \& Cani, P. D. (2011). Gut microbiota and the pathogenesis of insulin resistance. Current diabetes reports, 11(3), 154. 
Di Cerbo, A., Palmieri, B., Aponte, M., Morales-Medina, J. C., \& Iannitti, T. (2015). Mechanisms and therapeutic effectiveness of Lactobacilli. Journal of clinical pathology, jclinpath-2015.

Diakogiannaki, E., Pais, R., Tolhurst, G., Parker, H. E., Horscroft, J., Rauscher, B., ... Reimann, F. (2013). Oligopeptides stimulate glucagon-like peptide-1 secretion in mice through proton-coupled uptake and the calcium-sensing receptor. Diabetologia, 56(12), 2688-2696.

Doré, J., Multon, M.-C., Béhier, J.-M., \& participants of Giens XXXII, Round Table No. 2. (2017). The human gut microbiome as source of innovation for health: Which physiological and therapeutic outcomes could we expect? Therapie, 72(1), 21-38. https://doi.org/10.1016/j.therap.2016.12.007

Drissi, F., Raoult, D., \& Merhej, V. (2017). Metabolic role of Lactobacilli in weight modification in humans and animals. Microbial pathogenesis, 106, 182-194.

FAO/WHO. (2002). Joint FAO/WHO working group report on drafting guidelines for the evaluation of probiotics in food. FAO/WHO London, ON.

Fernandez, L. M. B., Lasa, J. S., \& Man, F. (2014). Intestinal microbiota: its role in digestive diseases. Journal of clinical gastroenterology, 48(8), 657-666.

Foligne, B., Nutten, S., Grangette, C., Dennin, V., Goudercourt, D., Poiret, S., Dewulf, J., Brassart, D., Mercenier, A, \& Pot, B. (2007). Correlation between in vitro and in vivo immunomodulatory properties of lactic acid bacteria. World journal of gastroenterology: WJG, 13(2), 236.

Fooks, L. J., \& Gibson, G. R. (2002). Probiotics as modulators of the gut flora. British Journal of Nutrition, 88(S1), s39-s49. 
Gionchetti, P., Lammers, K. M., Rizzello, F., \& Campieri, M. (2005). VSL\# 3: an analysis of basic and clinical contributions in probiotic therapeutics. Gastroenterology Clinics, 34(3), 499-513.

Holst, J. J. (2007). The physiology of glucagon-like peptide 1. Physiological reviews, 87(4), 1409-1439.

Hugas, M., \& Monfort, J. M. (1997). Bacterial starter cultures for meat fermentation. Food chemistry, 59(4), 547-554.

Jankovic, I., Ventura, M., Meylan, V., Rouvet, M., Elli, M., \& Zink, R. (2003). Contribution of aggregation-promoting factor to maintenance of cell shape in Lactobacillus gasseri 4B2. Journal of bacteriology, 185(11), 3288-3296.

Jayasinghe, T. N., Chiavaroli, V., Holland, D. J., Cutfield, W. S., \& O’Sullivan, J. M. (2016). The new era of treatment for obesity and metabolic disorders: evidence and expectations for gut microbiome transplantation. Frontiers in cellular and infection microbiology, 6, 15.

Johansson, H., Boesgaard, M. W., Nørskov-Lauritsen, L., Larsen, I., Kuhne, S., Gloriam, D. E., Bräuner-Osborne, H., \& Sejer Pedersen, D. (2015). Selective Allosteric Antagonists for the G Protein-Coupled Receptor GPRC6A Based on the 2Phenylindole Privileged Structure Scaffold. Journal of Medicinal Chemistry, 58(22), 8938-8951. https://doi.org/10.1021/acs.jmedchem.5b01254

Kawano, M., Miyoshi, M., Ogawa, A., Sakai, F., \& Kadooka, Y. (2016). Lactobacillus gasseri SBT2055 inhibits adipose tissue inflammation and intestinal permeability in mice fed a high-fat diet. Journal of nutritional science, 5.

Kechaou, N., Chain, F., Gratadoux, J.-J., Blugeon, S., Bertho, N., Chevalier, C., Le Goffic, R., Courau, S., Molimard, P., Chatel, J.M., Langella, P., Bermúdez-Humarán, L. G. (2013). Identification of One Novel Candidate Probiotic Lactobacillus plantarum 
Strain Active against Influenza Virus Infection in Mice by a Large-Scale Screening. Applied and Environmental Microbiology, 79(5), 1491-1499. https://doi.org/10.1128/AEM.03075-12

Klingberg, T. D., Pedersen, M. H., Cencic, A., \& Budde, B. B. (2005). Application of measurements of transepithelial electrical resistance of intestinal epithelial cell monolayers to evaluate probiotic activity. Applied and environmental microbiology, 71(11), 7528-7530.

Law, J., \& Haandrikman, A. (1997). Proteolytic enzymes of lactic acid bacteria. International Dairy Journal, 7(1), 1-11.

Lebrun, L. J., Lenaerts, K., Kiers, D., de Barros, J.-P. P., Le Guern, N., Plesnik, J., Thomas, C., Bourgeois, T., Dejong, C.H.C., Kox, M., Hundscheid, I.H.R., Khan, N.A., Mandard, S., Deckert, V., Pickkers, P., Drucker, D.J., Lagrost, L., \& Grober, J.. (2017). Enteroendocrine L cells sense LPS after gut barrier injury to enhance GLP-1 secretion. Cell reports, 21(5), 1160-1168.

Liou, A. P., Chavez, D. I., Espero, E., Hao, S., Wank, S. A., \& Raybould, H. E. (2011). Protein hydrolysate-induced cholecystokinin secretion from enteroendocrine cells is indirectly mediated by the intestinal oligopeptide transporter PepT1. American Journal of Physiology - Gastrointestinal and Liver Physiology, 300(5), G895-G902. https://doi.org/ $/$ b $\left.><\mathrm{i}\rangle \mathrm{ST} \_51</ \mathrm{i}\right\rangle\langle/ \mathrm{b}\rangle$

Liu, M., Bayjanov, J. R., Renckens, B., Nauta, A., \& Siezen, R. J. (2010). The proteolytic system of lactic acid bacteria revisited: a genomic comparison. BMC genomics, 11(1), 36.

Macho-Fernandez, E., Valenti, V., Rockel, C., Hermann, C., Pot, B., Boneca, I. G., \& Grangette, C. (2011). Anti-inflammatory capacity of selected Lactobacilli in experimental colitis is driven by NOD2-mediated recognition of a specific 
peptidoglycan-derived muropeptide. Gut, gut.2010.232918. https://doi.org/10.1136/gut.2010.232918

764

765

766

767

768

769

770

771

772

773

774

775

776

777

778

779

780

781

782

783

784

785

786

Margono, T., Sumaryono, W., Malik, A., \& Sadikin, M. (2014). Characterization of TrypsinLike Protease of Lactobacillus plantarum FNCC 0270. HAYATI Journal of Biosciences, 21(2), 87-94.

Meijerink, M., Wells, J. M., Taverne, N., de Zeeuw Brouwer, M.-L., Hilhorst, B., Venema, K., \& van Bilsen, J. (2012). Immunomodulatory effects of potential probiotics in a mouse peanut sensitization model. FEMS Immunology \& Medical Microbiology, 65(3), 488496.

Messaoudi, S., Madi, A., Prévost, H., Feuilloley, M., Manai, M., Dousset, X., \& Connil, N. (2012). In vitro evaluation of the probiotic potential of Lactobacillus salivarius SMXD51. Anaerobe, 18(6), 584-589.

Morelli, L. (2000). In vitro selection of probiotic Lactobacilli: a critical appraisal. Current Issues in Intestinal Microbiology, 1(2), 59-67.

Nadkarni, P., Chepurny, O. G., \& Holz, G. G. (2014). Regulation of glucose homeostasis by GLP-1. In Progress in molecular biology and translational science (Vol. 121, p. 2365). Elsevier.

Oya, M., Kitaguchi, T., Pais, R., Reimann, F., Gribble, F., \& Tsuboi, T. (2013). The G protein-coupled receptor family C group 6 subtype A (GPRC6A) receptor is involved in amino acid-induced glucagon-like peptide-1 secretion from GLUTag cells. Journal of Biological Chemistry, 288(7), 4513-4521.

Panwar, H., Calderwood, D., Gillespie, A. L., Wylie, A. R., Graham, S. F., Grant, I. R., Grover, S. \& Green, B. D. (2016). Identification of lactic acid bacteria strains modulating incretin hormone secretion and gene expression in enteroendocrine cells. Journal of Functional Foods, 23, 348-358. 
Park, J.-E., Oh, S.-H., \& Cha, Y.-S. (2014). Lactobacillus brevis OPK-3 isolated from kimchi inhibits adipogenesis and exerts anti-inflammation in 3T3-L1 adipocyte. Journal of the Science of Food and Agriculture, 94(12), 2514-2520.

Perdigon, G., Galdeano, C. M., Valdez, J. C., \& Medici, M. (2003). Interaction of lactic acid bacteria with the gut immune system. European journal of clinical nutrition, 56(S4), S21.

Quigley, E. M. M. (2013). Bugs on the brain; brain in the gut—seeking explanations for common gastrointestinal symptoms. Irish journal of medical science, 182(1), 1-6.

Ramos, C. L., Thorsen, L., Schwan, R. F., \& Jespersen, L. (2013). Strain-specific probiotics properties of Lactobacillus fermentum, Lactobacillus plantarum and Lactobacillus brevis isolates from Brazilian food products. Food microbiology, 36(1), 22-29.

Rose, C., Camus, A., \& Schwartz, J. C. (1988). A serine peptidase responsible for the inactivation of endogenous cholecystokinin in brain. Proceedings of the National Academy of Sciences, 85(21), 8326-8330.

Rose, Christiane, Vargas, F., Facchinetti, P., Bourgeat, P., Bambal, R. B., Bishop, P. B., Chan, S.M., Moore, A.N., Ganellin, C.R., \& Schwartz, J.-C. (1996). Characterization and inhibition of a cholecystokinin-inactivating serine peptidase. Nature, 380(6573), 403.

Sánchez, B., Delgado, S., Blanco-Míguez, A., Lourenço, A., Gueimonde, M., \& Margolles, A. (2017). Probiotics, gut microbiota, and their influence on host health and disease. Molecular nutrition \& food research, 61(1), 1600240.

Sanders, M. E. (2016). Probiotics and microbiota composition. BMC medicine, 14(1), 82.

Stenman, L. K., Burcelin, R., \& Lahtinen, S. (2016). Establishing a causal link between gut microbes, body weight gain and glucose metabolism in humans-towards treatment with probiotics. Beneficial microbes, 7(1), 11-22. 
811 Stubbendieck, R. M., Vargas-Bautista, C., \& Straight, P. D. (2016). Bacterial communities: interactions to scale. Frontiers in microbiology, 7, 1234.

Takemura, N., Okubo, T., \& Sonoyama, K. (2010). Lactobacillus plantarum strain No. 14 reduces adipocyte size in mice fed high-fat diet. Experimental biology and medicine, 235(7), 849-856.

Timmerman, H. M., Koning, C. J. M., Mulder, L., Rombouts, F. M., \& Beynen, A. C. (2004). Monostrain, multistrain and multispecies probiotics — a comparison of functionality and efficacy. International journal of food microbiology, 96(3), 219-233.

Tripp, C. S., Wolf, S. F., \& Unanue, E. R. (1993). Interleukin 12 and tumor necrosis factor alpha are costimulators of interferon gamma production by natural killer cells in severe combined immunodeficiency mice with listeriosis, and interleukin 10 is a physiologic antagonist. Proceedings of the National Academy of Sciences, 90(8), $3725-3729$.

Uyemura, K., Demer, L. L., Castle, S. C., Jullien, D., Berliner, J. A., Gately, M. K., Warrier, R.R., Pham, N., Fogelman, A.M., \& Modlin, R. L. (1996). Cross-regulatory roles of interleukin (IL)-12 and IL-10 in atherosclerosis. The Journal of clinical investigation, 97(9), 2130-2138.

Vaughan, E. E., \& Mollet, B. (1999). Probiotics in the new millennium. Food/Nahrung, 43(3), $148-153$.

Vezzoli, G., Soldati, L., \& Gambaro, G. (2009). Roles of calcium-sensing receptor (CaSR) in renal mineral ion transport. Current pharmaceutical biotechnology, 10(3), 302-310.

Wang, J., Tang, H., Zhang, C., Zhao, Y., Derrien, M., Rocher, E., van-Hylckama Vlieg, J.E., Strissel, K., Zhao, L., Obin, M., \& Shen, J. (2015). Modulation of gut microbiota during probiotic-mediated attenuation of metabolic syndrome in high fat diet-fed mice. The ISME journal, 9(1), 1. 
836 Watson, D. C., Sargianou, M., \& Panos, G. (2012). Interleukin-12 (IL-12)/IL-10 Ratio as a Marker of Disease Severity in Crimean-Congo Hemorrhagic Fever. Clinical and Vaccine Immunology, 19(5), 823-824. https://doi.org/10.1128/CVI.00030-12

Wellendorph, P., Hansen, K. B., Balsgaard, A., Greenwood, J. R., Egebjerg, J., \& BräunerOsborne, H. (2005). Deorphanization of GPRC6A: a promiscuous L-alpha-amino acid receptor with preference for basic amino acids. Molecular Pharmacology, 67(3), 589-597. https://doi.org/10.1124/mol.104.007559

Yadav, H., Lee, J.-H., Lloyd, J., Walter, P., \& Rane, S. G. (2013). Beneficial metabolic effects of a probiotic via butyrate-induced GLP-1 hormone secretion. The Journal of Biological Chemistry, 288(35), 25088-25097. https://doi.org/10.1074/jbc.M113.452516

Zebisch, K., Voigt, V., Wabitsch, M., \& Brandsch, M. (2012). Protocol for effective differentiation of 3T3-L1 cells to adipocytes. Analytical Biochemistry, 425(1), 88-90. https://doi.org/10.1016/j.ab.2012.03.005

Zhang, C., Liu, H., Chen, S., \& Luo, Y. (2018). Evaluating the effects of IADHFL on inhibiting DPP-IV activity and expression in Caco-2 cells and contributing to the amount of insulin released from INS-1 cells in vitro. Food \& Function, 9(4), 2240-2250. https://doi.org/10.1039/C7FO01950E

Zietek, T., \& Rath, E. (2016). Inflammation Meets Metabolic Disease: Gut Feeling Mediated by GLP-1. Frontiers in Immunology, 7, 154. https://doi.org/10.3389/fimmu.2016.00154 
Figures captions:

860

861 Figure. 1 Immunomodulation capacities of the selected strains

862 Peripheral blood mononuclear cells (PBMCs) derived from human blood were stimulated in 863 vitro with freshly cultured bacteria at a ratio of 10:1 (bacteria/cells) for $24 \mathrm{~h}$. B. longum strain

864 was added as anti-inflammatory control and L. lactis MG1363 strain as pro-inflammatory 865 control. Control PBMCs were only treated with PBS buffer. Levels of IL-10 (A), IL-12 (B) 866 and IFN $\gamma(\mathrm{C})$ were measured by ELISA in the supernatant after $24 \mathrm{~h}$ stimulation with the 867 selected bacteria. GraphPad Prism was employed for graph preparation and statistical 868 evaluation. Differences between groups were assessed using ANOVA, followed by 869 nonparametric Mann-Whitney test. Data with $\mathrm{p}$ value $\leq 0.05$ were considered to be significant. 870

Figure. 2 Capacity of the selected lactobacilli to restore or strengthen epithelial barrier 872 in polarized Caco-2 monolayers sensitized with hydrogen peroxide $\left(\mathrm{H}_{2} \mathrm{O}_{2}\right)$.

873 Caco-2 monolayers were treated at the apical side with the bacteria (at 10:1 bacteria/cell ratio) $87430 \mathrm{mn}$ before the addition of $\mathrm{H}_{2} \mathrm{O}_{2}(100 \mu \mathrm{M})$. Changes in trans-epithelial electrical resistance 875 (TEER) across Caco-2 cell monolayers were measured before the addition of $\mathrm{H}_{2} \mathrm{O}_{2}(\mathrm{~T} 0)$ and 876 every $30 \mathrm{mn}$ until $120 \mathrm{mn}$. Results were expressed as \% TEER compared to T0. Values 877 represent the mean of 3 repeated experiments. Means without a common letter are different $878(\mathrm{p}<0.05)$ using one way ANOVA with Tukey post hoc test for pairwise comparisons.

879

880 Figure. 3 Capacity of the strains to limit lipid accumulation.

881 Mature 3T3-L1 derived adipocytes were treated for $24 \mathrm{~h}$ with the bacteria (10:1 bacteria/ cell 882 ratio). Lipid content was compared using red-oil staining and reported in percentage of level 883 obtained with lactobacilli-treated cells versus control untreated cells (normalized at 100\%). 884 Values are the mean of four repeated experiments. Means without a common letter are 885 different $(\mathrm{p}<0.05)$ using one way ANOVA with Tukey post hoc test for pairwise comparisons. 886

887 Figure. 4 Capacity of the strains to induce the release of gut peptides and impact of 888 specific antagonists of CasR and GPRC6A and Pept-1 inhibitor.

889 CasR antagonist NPS $2143(25 \mu \mathrm{M}$, dark grey bars), GPRC6A antagonist CpD (50 $\mu \mathrm{M}$, grey 890 bars) and Pept-1 inhibitor AMBA-4 (10 mM, black bars) were added (or not, white bars) 15 891 mn prior the addition of the bacteria and active Glucagon-Like Peptide 1 "GLP-1" (A) and 
892 cholecystokinin "CCK" (B), secreted by STC-1 cells were measured by RIA. Values are 893 expressed in fold of untreated control cells without inhibitors treatment and are means \pm SD 894 of three repeated experiments. Means without a common letter are different $(\mathrm{p}<0.05)$ using 895 one way ANOVA with Tukey post hoc test for pairwise comparisons in each inhibitor 896 condition. $* \mathrm{p}<0.05$ vs. control.

897

898 Figure. 5 Capacity of selected strains to degrade GLP-1 (A) and CCK (B).

899 (A) GLP-1 1-26 (800 pM) and (B) CCK8S (600 pM) were treated with bacteria (at $10^{7}$ 900 CFU.mL ${ }^{-1}$ ) in the presence (grey bars) or absence (black bars) of DDP-IV inhibitor for $8 \mathrm{~h}$. 901 Remaining quantities of each hormone were measured by RIA and expressed in percentage of 902 control without treatment. Values are expressed in percentage of control and are means \pm SD 903 of three repeated measurements. Means without a common letter are different $(\mathrm{p}<0.05)$ using 904 one way ANOVA with Tukey post hoc test for pairwise comparisons. 
Figure 1.

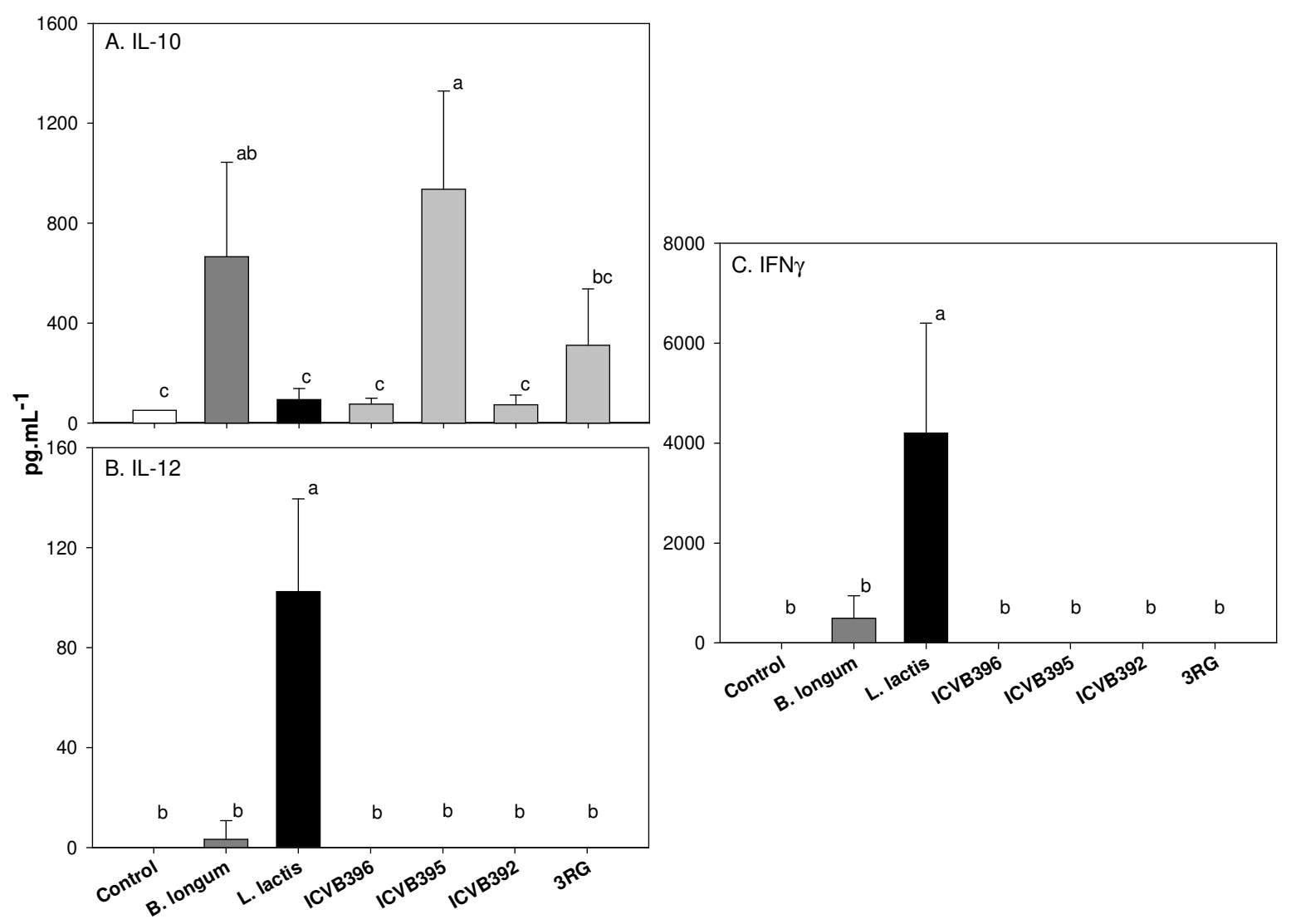


Figure 2.

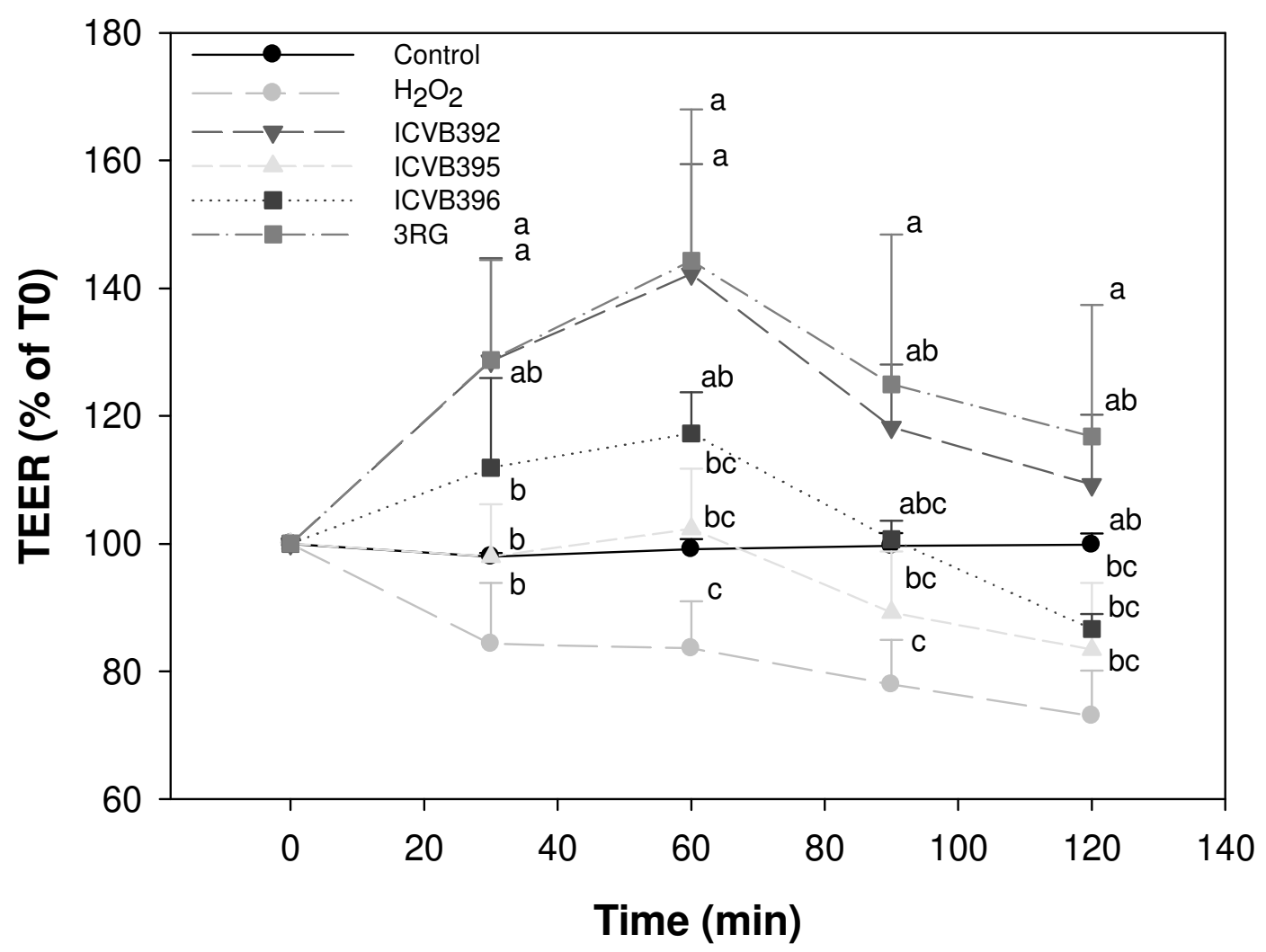


Figure 3.

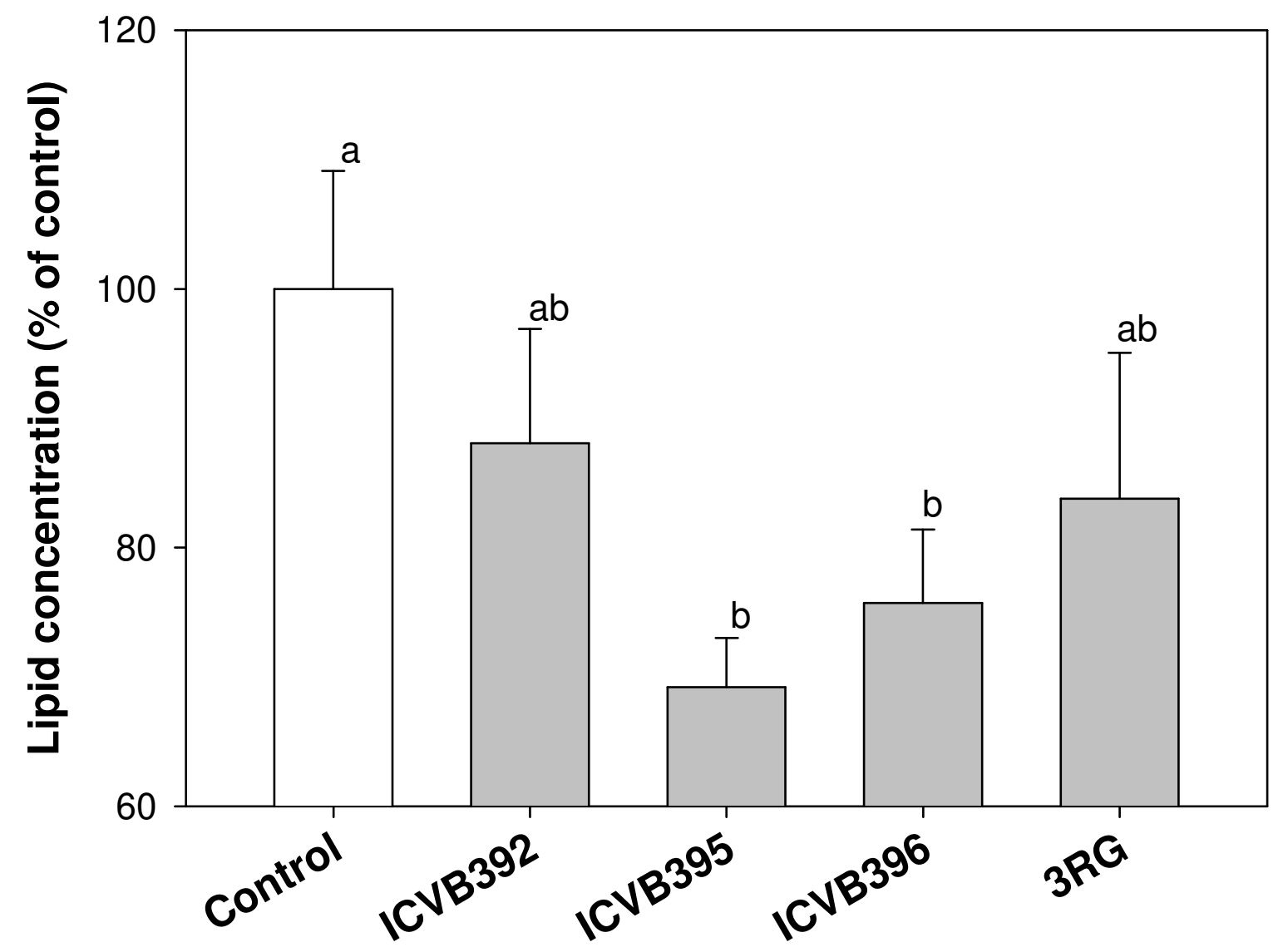


Figure 4.
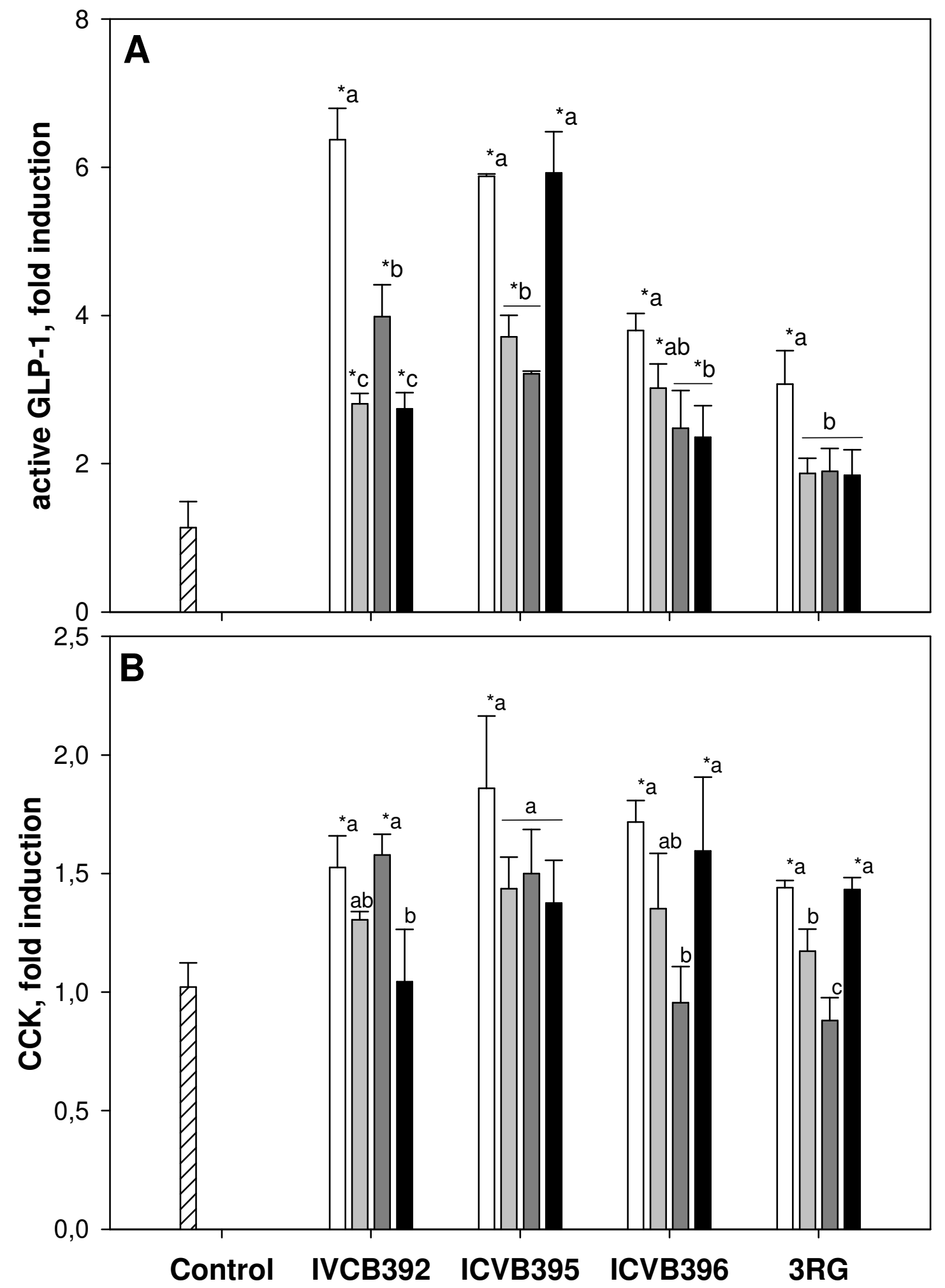
Figure 5.
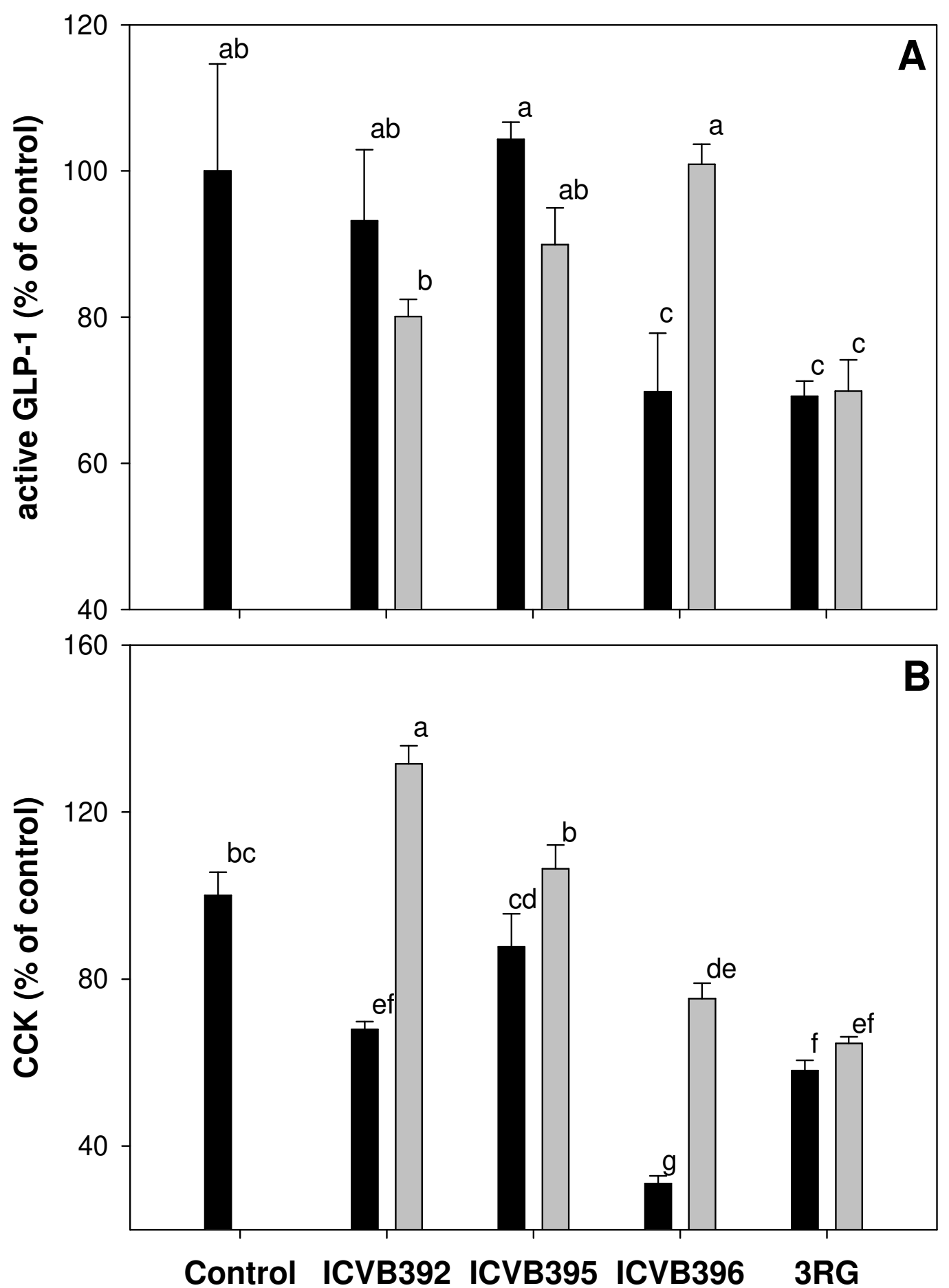

Control ICVB392 ICVB395 ICVB396 3RG 